This is the peer reviewed version of the following article: Lo Bianco, Joseph (2010). The importance of language policies and multilingualism for cultural diversity, International Social Science Journal 61(199), 37-67, which has been published in final form at DOI: 10.1111/j.14682451.2010.01747.x. This article may be used for non-commercial purposes in accordance with Wiley Terms and Conditions for Self-Archiving.

\title{
The importance of language policies and multilingualism for cultural diversity
}

\author{
Joseph Lo Bianco
}

\section{Introduction: language policies and multilingualism}

While human intervention to direct and influence the form and use of language is probably as old as language itself, conscious and planned policy-making, or deliberate language planning, is much more recent. Human societies have always been multilingual and language planning, whether overt and conscious or covert and implicit in other activity, has always existed. Language planning has been directed towards changes either within individual languages or across diverse languages, targeting the communication patterns of a community.

During the 1950s and 1960s, an era of large-scale decolonisation in Africa and Asia in which a large number of new nations were forged, a new kind of language policy and planning arose. This aspired to resemble the efficient processes of general public policy-making, and therefore to be a systematic, technical, and even a scientific enterprise. In such a program experts and expertise would guide what were essentially rational, planned and mechanistic approaches to the roles and functions of languages in multilingual societies. In some cases these approaches, and the theories that supported them, aimed at a kind of language engineering. The main fields of knowledge which informed this emergent discipline were applied linguistics and sociolinguistics, sub-branches of the formal study of language. The last decades of the twentieth century were also a time of great experimentation in language policy and planning. In the wake of immense changes in global political arrangements, including rapid, pervasive and deep economic globalisation producing vast population mobility, many new nations emerged, some old nations achieved statehood and other nations became multicultural for the first time. However, a more sober sentiment prevailed in the applied language sciences, characterised by more modesty about the prospects of a rational and technical language policy and planning, and even less ambition to aspire to scientific or engineering certainty. Informing the study and practice of policy-making for languages today, in addition to the language sciences, are the fields of economics and the political and human sciences, as well as an awareness of the profound consequences of digital and electronic communications. This more sober mood is well captured by the noted Filipino linguist and educator, Andrew Gonzalez, who, in the context of national surveys documenting the communication patterns in that densely multilingual society, famously commented, "benign neglect is better than deliberate language planning" (Gonzalez and Bautista 1986; Hau and Tinio 2003, p.337).

Gonzalez was reflecting on some failures of deliberate language planning. Intervention to direct the fortunes of individual languages or to influence language use in multilingual societies frequently does not produce what planners aim to achieve. This is because language is an immensely supple and complex set of practices, a socially produced system of semiotics that interacts closely with all aspects of people's social and personal lives. Identity, both personal and social, and economic and national interests, as well as collective and individual memory are all constructed through language or are realised and negotiated in acts of communication. Without one of the products of language, writing, it is impossible to imagine civilisation. Some aspects of spoken, preliterate language resembles written language literacy in the genres through which it is organised, thereby facilitating memory, the recall of information and the organisation of social groups. In these ways, language makes possible practically all social interactions, identities and civilisation itself.

In strictly linguistic terms all languages are equal. For the linguistic sciences all languages are capable of expressing the intentions and needs of their users, of being developed to expand into new domains and express extended meanings. But in the contemporary alignments of socio-political, technological and economic affairs there is abundant inequality between languages. Some languages 
are much more developed terminologically, stabilised by dictionaries, codified by specialist academies, supported in formal education systems, invested with the prestige of elite literature and science and backed up by vast publishing industries and dissemination systems. Most world languages lack some, most or all of these bolsters. Some languages are projected beyond their original territorial zones by powerful national or imperial economies and political systems, or disseminated through the industries of written, music, or celluloid culture that devise and project desirable identities; images made available globally to attract emulation and stimulate desire.

If the inequalities represented by such disparities in social power, opportunity, mobility and material advancement are ignored by language planners and activists for language rights on behalf of marginalised or minority languages, language policies, no matter how well-intentioned, will not succeed in achieving their aims. Even the languages of small nation-states, though supported by the apparatus of compulsory education, backed by codified and standardised literacy, public administration and institutional preference increasingly borrow large parts of their terminology from the world's dominant languages and deliver more and more of their higher education content through a handful of languages of wider communication, pre-eminently English. There are only around 200 states in the world, and nearly all sustain one or at most a few languages with state functions, so the vast bulk of the almost 7000 human languages lacks state support. Many languages are threatened with outright extinction.

Languages are closely connected with symbolic power and have material consequences for their users. Under conditions of market economics and globalisation language policies must acknowledge a dual principle of the demand for access to linguistic codes of wider communication and the complementary importance of conserving the unique cultural resources contained in multilingualism.

There are many examples of indifferent outcomes from language policies. Some of these failures or unremarkable successes relate to policies supporting minority languages or supporting the replacement of inherited colonial languages by indigenous languages, or policies advancing the teaching of foreign languages that have strategic or economic importance in developed country education systems.

Planners of language, students of language planning and language rights activists must acknowledge that even the best-conceived and most sincerely motivated language plans are unlikely to succeed if the prevailing forces of economic, technological and political change are working actively against the intentions of planners. These observations should induce language planners to acknowledge more fully how language and communication interact with and reflect wider social arrangements and, while remaining humble about what deliberate intervention can be realistically expected to achieve, to be determined in devising new modes of language policy and planning that can achieve the goals of supporting multilingualism and cultural diversity.

It should also be stated at the outset that neglect is not always benign, at least not for minority languages under conditions of globalisation. All parts of the world are rapidly being embraced by information and communications technologies, forms of social identity and organisation and consumerist capitalism formed around a single interconnected global market. There is an urgent need for successful, guided language policy-making in the face of the relentless effects of economic globalisation and the deep and still not fully understood impacts on communication of technological advancement, especially ubiquitous and instantaneous digital communication, not to mention galloping environmental degradation. All of these forces and trends have exposed many small language communities and their distinctive lifestyles to considerable pressure.

The term, a language under pressure, refers to a language some of whose speakers live under political, social, economic or cultural conditions that induce them to transfer to communicating in a different, dominant, language. If such pressures persist across generations languages under pressure become endangered. They are "locally endangered" when only one or a few communities of speakers are under pressure but become "globally endangered" when all their speakers come under pressure to shift (Fishman 2001; Robins and Uhlenbeck 1991; Schmidt 1993: Wurm 2001). Today most of the world's languages may have reached some level of attrition, and many face the latter and extreme position and are on the verge of extinction. Should this come about it would represent an extraordinary and unprecedented contraction in the cultural condition of humanity. So far as we know it would be the only time in human existence during which our communicative means, whether in 
speech or in signs, would not be marked by immense diversity.

In response to this empirical condition of language endangerment there is widespread alarm about both its cultural consequences and the effects on the environment. The intimate connection between the erosion of the natural ecological diversity of the world and linguistic-cultural diversity is increasingly appreciated. The erosion of biological diversity is accompanied by, and probably in turn contributes to, the equally devastating loss of human cultural diversity, most sharply represented by the loss of languages (Skutnab-Kangas et al., 2003). The loss of history, memory, cultural knowledge, diverse practices, norms and values that such a loss represents has been well documented (Diamond, 2001; Grenoble and Whaley, 1998; Mühlhäusler, 1996; Nettle and Romaine, 2000).

Perhaps even exacerbating this is the often overlooked fact that of all the markers of human difference, such as ethnicity and racial affiliation, religious or ideological belief, physical biology, age and seniority, social class, gender and sexuality, language is the most plastic and plural. Language is the one marker of cultural diversity that allows individuals to add and multiply in a theoretically limitless way. It is difficult or impossible to embrace more than one of the other markers of human difference (gender, race, ancestry, nation, religion), whereas individuals can continually acquire, extend and enrich languages.

The Council of Europe (Beacco 2007) distinguishes between multilingualism as a characteristic of societies and plurilingualism as a characteristic of individuals. Societies are marked by the complex array of language competencies among their members. Multilingual societies are composed of diverse communication groupings with overlapping shared communication competencies, as well as vertical stratification and horizontal separation. Opponents of multilingualism often claim that it produces social disruption and conflict because people are unable to communicate with each other but this confounds two very different entities. Social cohesion and common citizenship require shared forms of communication and comprehension, not monolingualism. There is no necessary connection between the number of languages in a given society and its ability to engage in cross-group communication. Societies have a right to expect the latter but they make a profound mistake in assuming that this requires a contraction in diversity.

Many language communities are distributed across diverse parts of the world. Through migration, colonial expansion, refugee displacement, tourism or professional mobility, many language communities are now dispersed. Their speakers identify with diverse local settings in diasporas as well as with original homelands. Connections between language and place have become multiple. In particular places communication patterns are also highly varied, which is sometimes characterised by code-switching, the use of gesture, bilingualism, different receptive and productive competencies in different languages or dialects, and it is marked by mixtures of full, partial and specialised proficiencies. In keeping with this complex and varied communicative reality typical today of the global megalopolis which is the living space of most humans, human identities are multiple and distributed across ethnic, gender, personal, professional, regional, recreational, ideological, religious, nationality and other dimensions.

In these complex and heterogeneous conditions languages reflect many kinds of identity. They may be particular, national and universal, such as local histories and cultures, elite histories and cultures from originary sources and places, such as identities that are given authority by states or by prestigious literature and elevated individuals, and functional universal identities and cultures. Beyond identities associated with local, national and transnational geopolitical space there are also languagemediated identities that disrupt established identities, as well as language practices that are subversive and transgressive, in that they deny the power and role of authorities whether these are local, national or transnational.

It is clear from observing how multilingual societies and plurilingual individuals actually operate in ordinary concrete communication, rather than in the imagined, idealised and purist settings or modes, that languages can express multiple identities and support diverse cultural forms. By this kind of reasoning the words Arabic, English, French or Spanish are broad designations, categories that name places and historical traditions, language names for what in the final analysis are communicative practices enacted across vast areas of the globe, whose names nominate a place of origin rather than a state of use. But each of these and many other languages as well, animate diverse cultural traditions in a wide range of dispersed geopolitical entities. Today there is a vast field of scholarship 
on the pluralised notion of "Englishes" in recognition of its immense geographical penetration, which, it is projected, will be familiar to close to half the world's population at some imminent future point (Graddol 2006). Stimulated by research on the "Indianness" of Indian varieties of English (Kachru 1983, 1986) scholarship on the diversity of world Englishes has come to reveal the immensely complex modes in which language, identity and relationships interact and how speakers fashion the forms of language they inherit into concrete meaning making resources in new environments and for new purposes.

This body of studies complements rather than contradicts a different but apparently dissenting branch of research. The latter supplies evidence that the original or formative cultural milieu of a language, such as English, remains imprinted on its grammatical and lexical forms, persisting in the structure of the language like a recurring cultural message, even when that language is transported to vastly different new contexts (Lo Bianco 2007a; Wierzbicka 2006). Languages contain cultural signifiers, like meaning potentials, which reveal or expose their origins but, when transposed to different settings expressing different experiences and new cultural patterns and purposes, the new users and new uses transform these potential meanings into locally creative or hybrid expressions. "Englishes" are only the largest instance of how single languages can be transformed to express multiple cultural meanings. The importance of this point is to stress that, although languages have homes and origins that might remain imprinted in them, they are not singular and unvarying, attached to single geopolitical and cultural spaces or to points in time. Nor are they the exclusive property of particular groups. When languages are made to do new cultural work in new settings their ownership is transferred to new users. Cultural diversity resides within single languages as well as across languages. This, however, is not the sociological reality of most of the world's languages, which are specific to particular environments and speaker communities and reflect the density of references to those spaces and speakers. The intimacy of relations between some languages and some places is one of the primary legitimisations for a policy of multilingualism.

The central role that languages play in the formation of meaning and identity requires that any project of sustaining cultural pluralism and diversity should make the maintenance of multilingualism a central objective. In light of this, a guiding principle of the present article is that policies for cultural diversity need to be grounded in two objectives: the goal of shared, more accessible and fairer communication across the regions, nations, peoples and great traditions of the world, and the complementary, but different, objective of strengthening and maintaining the diversity of language and the cultural diversity and difference that these languages uniquely express.

\section{Language and cultural diversity}

\section{Multilingualism}

Approximately one-third of all spoken languages of the world are found in Asia and another one-third in a small number of Pacific Island countries, but only about 3 per cent are found in Europe (Gordon 2005). The nation-state is the social and political formation within which the depletion of languages has occurred in Europe and is today the principal instrument of linguistic depletion globally.

Prior to the establishment of states based on overriding commitment to a single and exclusive national identity, people's cultural attachments and practices of sociality were localised. Combined with an overarching identity entrusted to transcendent beliefs of religion or to dynastic, monarchical or imperial authorities which did not demand cultural affiliation, this pattern facilitated extensive local cultural diversity and language pluralism. Rulers desired of their subjects only that they obey laws, pay taxes and refrain from fomenting rebellion. The nation- state, by contrast, aims to induct its citizens into comprehensive and universal cultural formations. Nationality is bounded by territory but demands homogeneity within that territory and adherence to specific narratives of history and destiny. The overriding instrument for such processes was the idea of an overarching and common national culture but this was reinforced by the pragmatic operations of the state: taking censuses, public education, serving in a permanent military, the spread of newspapers and other media (Anderson 1991; Gellner 1983), policing territory and managing a national economy. Through its need for mass, basic and compulsory literacy in standard languages, industrialism intensified and widened this process. 
In 1993 UNESCO adopted a project entitled "The Red Book of Languages in Danger of Disappearing" as part of its discussions on the preservation of intangible cultural heritage. Aiming to document the number and state of endangered languages this process resulted in the creation of an International Clearing House and Data Bank Centre for Endangered Languages at Tokyo University in 1995. The imprecision in the figures, as calculated by expert professional linguists who use mostly outsider criteria to determine what constitutes a language, is of considerable interest. The various editions of the Ethnologue database (Gordon 2005) indicate that whatever the precise total of languages that experts estimate exist, speakers nominate a vastly greater number. According to the 14th edition of Ethnologue some 41,000 speaker names, what might be called insider names, correspond to the 6700-7000 expert names for languages. This disparity between insider and outsider perceptions of what constitutes a language, and what its proper name should be, suggests more than that insiders imagine they speak many more distinctive languages than the calculations of experts allow. This difference of perspective points to one of the reasons why language death causes concern. Subjectivity and "insiderness" collectively represent a vast inheritance of intellectual and cultural perspectives on reality and experience.

Half of the languages threatened with extinction have fewer than 10,000 speakers and half of these have fewer than 1000 speakers. This means that 8 million people or 0.2 per cent of the world's population speak half the world's languages (Gordon 2005; Krauss 1992). Conserving alternate world-views has become a key justification why people other than speakers of threatened languages are committed to their retention.

The anticipated loss of most of the world's languages is claimed to have a detrimental, even devastating, impact on various kinds of diversity; both human modes of diversity such as world-views and values and ecological and natural environments. As languages are intimately associated with the development and dissemination of knowledge many communities and academic researchers argue (Hinton and Hale, 2001; Mühlhäusler 1996; Scanlon and Singh 2003; Skutnabb-Kangas 1998) that language loss depletes stocks of knowledge in cultural, technical, scientific, medical and environmental spheres. This body of writing notes that medical and scientific innovations, new crops and new markets, and especially the management of unique bio-ecology spheres, will be more feasible if we can retain the intact social systems of traditional custodians, whose languages have named and brought into their daily discourses living relationships with diverse ecosystems. Sustainable land and water management, marine technology, plant cultivation, animal husbandry and weather are, by this logic, intimately bound up with language, culture and social systems in a mutually reinforcing matrix.

Many non-government organisations (NGOs) foundations and academic institutions and scholars have established alliances to support positive language policies for Indigenous languages that link the maintenance of language with the ecological movement. This movement resulted in a major international statement, the Declaration of Belém (Brazil) in 1988 called Cultural Diversity and Biological Diversity (International Society of Ethnobiology n.d.). Nettle and Romaine (2000) argue that the physical environment is an intrinsic part of traditional language ecologies. They show this absence of separation between the external environment and the description of that environment through their exploration of 10 of 12 megadiversity countries matching the top 25 endemic language diversity countries, pointing out that this means that most of the world's small languages which have been stable over time are in areas of major ecological richness. This is because relatively intact cultural systems and the local management of such systems have co-evolved so that small-scale human groups with local ecosystems have encoded and transmitted knowledge in local languages. What resultsis an interactive development of language and living, expressed by Mühlhäusler as follows: "Life in a particular human environment is dependent on people's ability to talk about it" (1996, p.155).

The view that biodiversity and linguistic diversity underpin and reinforce one another is now a wellestablished intellectual framework for mounting discourses for the protection of threatened languages (Maffi 2001; Skutnab-Kangas et al. 2003). The claimed mutual interdependence of biological and linguistic diversity has major implications for environmental practices, not least across formal academic disciplines such as linguistics and environmental sciences. During 2000 Terralingua, concerned with language rights, and the World Wildlife Fund for Nature (WWF), mapped the world's eco-regions, defined as species-diverse natural communities, under varying environmental conditions. Using ethno-linguistic criteria, the resulting report, Indigenous and traditional peoples of the world and 
eco-region conservation (Oviedo et al. 2000), nominated 874 eco-regions, some 238 being exemplars of various habitats, terrestrial, freshwater and marine. In a disproportionate number of cases these covary with small-scale language communities whose custodial relation with these zones is argued to be critical to their effective long-term sustainable management.

Article 5 of the 2001 UNESCO Cultural Diversity Declaration advances precisely this kind of justification for multilingualism. UNESCO has long been in the forefront of sounding the alarm about the effects of globalisation and economic modernity for the world's languages and a range of NGOs have long been active in this field. Since issuing its "Red Book of Languages", aiming to document and continually update information on endangered languages and promote research, UNESCO has stimulated many studies of language endangerment. The work of documentation is an essential component for counteracting the seemingly inexorable loss of the world's linguistic resources.

It is, of course, the case that biological species evolve as do human languages and cultures. But the extinction crisis in today's world has accelerated beyond any normal tendency of loss and regeneration, and development plans accelerated by economic globalisation and the reach of interconnected world markets have dispossessed many traditional peoples of their lands and endemic resources. Disrupted lifestyles and degraded physical environments combine with cultural and linguistic assimilation, producing a shift away from traditional languages towards the exclusive use of dominant national languages or sometimes creoles, together with the loss of inherent knowledge this entails. The conservation of natural environments requires, therefore, an integrated approach to the co-evolution and co-dependency of biological and cultural diversity, with languages as the critical mediating tool.

Compounding these considerations is the phenomenon of mass population movement on an unprecedented scale. All parts of the world are engaged in population transfers in all directions, impacting on all social categories (Castles and Miller 2003). In this vast mobility societies of emigration have been transformed into societies of immigration. New kinds of movement and residency have been created. All categories of people are engaged in extensive relocation: students, spouses and workers; the poor and the rich; the displaced and the curious; the temporary, the permanent and the continuous.

These kinds of multifaceted movements are accompanied by the increased facility of retaining contact through instantaneous electronic and digital communication across space which allows the continuation of connection despite the loss of proximity. In these flows of population, ideas and spaces most language communities have diasporas linked to homelands, and new settings for languages that were once tied to particular places, territories and zones, where identity and experience were forged. For many home languages now dispersed across the earth, identities are projected into imaginative realms, producing more varied and hybrid kinds of psychological association of place, identity and language in response to the need for belonging and attachment.

Minority communities, even when dispersed and isolated physically, potentially have available digital and electronic tools for the transfer of voice and image to multiple recipients in real time. It has often been predicted that global electronic communication, especially the Internet, would provoke a massive shift of language use towards a small number of privileged languages of wider communication, especially English. And yet these same tools are available for the language maintenance and regeneration of small, dispersed and isolated language communities and are potentially instruments for supporting multilingualism.

One undeniable major challenge is the threat to non-alphabetic writing although this threat to different scripts, especially to non-alphabetic writing systems, is being progressively reduced with the expansion and diversification of voice-based modes of communication, including the conversion of voice to writing.

\section{Memory and cultural formation}

Cultural groups are not formed solely by the physical proximity and social interaction that bring about shared experience. Indeed, it is not possible to imagine living closely and doing things together without the mediation of talk and writing. Talking and writing, and therefore language, are central to 
the formation of culture both because talk and writing mediate experience, and because the forms in which that experience is expressed and organised are essentially genres of language.

What is remembered is formulated in genres, whether in the mundane forms of stories, folk-tales, admonitions to infants, songs of work, endurance, suffering and struggle, aphorisms and proverbs, belief and ideology and the philosophy of common sense as contained in speech. All these are mediated in language, which also becomes the archive in which such knowledge is stored. In the more elevated and authoritative forms of literature, language again comes to be central in defining and giving contour and content to experience. In these and other ways, language, having the dual role of being the medium through which experience is encountered, discussed and recorded, and often itself being the object of cultural expression, is uniquely endowed with value for cultural diversity.

Language is also temporal in the sense that when we write and speak in the here and now, we validate the past meanings and uses of language. Most of the words, expressions and conventional meanings that we use here and now were devised before our use of them, and in using them we engage in a practice of confirming our connection with what we have inherited. This time-based function of language is tied to another function in the here and now: that of using language from the past to achieve our purposes in the present and to imagine, shape and bring about the future.

By living close together and interacting, people engage in dialogue, negotiate and discuss common experience. In this process we form negotiated conceptualisations that constitute templates for the particular group's thought and behaviour (Forgas et al. 2001; Rogoff 2003; Sharifian 2003; Valsiner and van der Veer 2000). These templates assist in making sense of and giving order to new or unprecedented experiences, including how to deal with other groups. These templates are "embodied" in cognition, in how people think about and how they come to know the world, taking the form of mental schemas, intellectual categories and conceptual metaphors. These are mental constructs that emerge from sociocultural interaction and are available to all individuals in a group, but are emergent at the level of cultural groups. Not all individuals and social groups share these in equal proportion and some contest or reject what a culture makes available.

Cultural conceptualisations arise from distributed cognition, that is, knowledge that is not exclusively personal or individualised is but shared, common or collective in nature (Bateson 1979; Hutchins 1995; Rieber 1989; Valsiner 2007). Cognition is instantiated in each individual but remains emergent at the collective level of a cultural group, and depends crucially on communication through human languages, which select out of the totality of experience those aspects or dimensions that become the object of attention or focus for particular cultures. In doing this differently, related languages diverge as the choices they make become progressively reinforced, passed on and re-circulated. Human communication is the locus for the negotiation and renegotiation of cultural conceptualisations, although they often materialise in artefacts and in non-verbal aspects of our behaviour.

\section{Intercultural awareness and "worldmindedness"}

Languages require us to use tools that an individual user of language has not personally invented, having been devised in preceding times, and re-circulated for long periods of time by others. In this way a new learner or a young user of a language is immediately connected in time and space to cultural traditions. This link with the past is a key way in which languages provide a unique form of access to other cultural traditions, in this case temporal traditions.

These insights have a practical educational consequence. When individuals study history, they encounter other times. In studying geography, they encounter other places. All learning involves individual learners in gaining knowledge and appreciation of otherness, that is, of the cultural conceptualisations that have shaped other groups' collective encounter with reality, whether it is other times, other places, or other practices, beliefs or values. Similarly, when individuals study different artistic traditions, religious beliefs or performance genres, they encounter semiotic systems, experiences and values that are made natural by other groups and in other settings. These diverge to the extent that different groups give prominence to different aspects of common human experiences or interpret that same need or experience in different ways. Ideally, this has the effect of encouraging individual learners to re-imagine their own assumptions about what is natural and normal, and to appreciate the productive, enriching perspective that diversity makes available, that is, intercultural 
awareness. Increased practice and skill in accepting the naturalness of different languages, effectively a multiplication of what is taken to be natural, can lead to intercultural competence. If this is extended significantly it can produce a disposition of worldmindedness, a state of thinking and an attitude that extends knowledge of difference and acceptance of its naturalness to groups and traditions beyond those the individual has directly studied and known.

Language policies have a vital role to play in advancing intercultural awareness, fostering intercultural competence and stimulating world-mindedness. This is because the bulk of foreign and secondlanguage teaching by definition aims to instil in the learners admiration of the studied group and its culture, traditions and achievements. Worldmindedness, on the other hand, seeks to invest this method of foreign language culture teaching with the much wider scope and ambition to generalise knowledge about the foreign culture studied to wider processes of communication and meaningmaking of human cultural groups in general, so that individual learners can gain insight beyond the personal self and the immediately studied Other.

In the same way that studies of comparative art, religion, philosophy, history or geography introduce otherness, languages take their place as a mode of encounter with human groups. However, unlike these other fields of study, languages have unique perspectives to offer individual language learners in dealing with difference and otherness. Knowing a language requires the individual to have more than simple knowledge, or cognition, of times past, places distant or abstract notions. Languages combine knowledge with behaviour. Using a language we are learning requires us to activate the new knowledge we gain, to perform this new knowledge in expressive and behavioural ways, to convert newly gained linguistic information into actual behaviour to perform tasks, make meaning and function effectively in the here and now of a different cultural system. This performative dimension links languages with cultural diversity in a special way, one that requires an individual language user to operate with the grammatical rules, communicative practices and expressive norms of the target language community in a naturalised way. In doing this, the language user adopts collective norms and assumptions and applies them in practical communication. Activating the internal knowledge the learner gains (including grammatical rules, word meanings, stocks of information, social groups and distinctions and forms of politeness) of the target language system means activating how the target language system has been culturally programmed by generations of its prior users and performing this inherited, culturally specific selection of conceptualisations in the present.

When we encounter or study and then use a language, we are engaged in performance but not the kind of performance that simulations, enactments or intercultural exercises might require, or as we might encounter in drama in which we play assigned roles. Language learning and use have the uniquely valuable quality of requiring new learners and old users alike to continually affirm the living patterns these languages contain, and to make them natural. In this respect, languages are essential to cultural diversity because they require us to confirm that the Other is natural in its own system of meaning and sense, and to conform to the rules of naturalness which that language system contains. This conforming and confirming is performative because languages require that we enact assumptions and practices that are both arbitrary (as multilingualism by definition means that no one language can claim categorical precedence over others) and ineluctable (because for native speakers of a language the world is defined in and through its categories and use).

If we are using Italian, for example, we must accept that doors, churches and the moon are feminine things while boots, temples, and pilots are masculine. If we are using Tamil we must accept and naturalise a wider view than the English system, in which entities in the world are agents capable of acting independently, and choose verb forms appropriately to allow these entities to be independent agents. If we are using Japanese we must expect that individuals have several personal identities and will project whichever one is appropriate in particular relations with others, and choose pronouns and other lexical items according to the person being addressed. If we are using English we encounter many social settings in which it is important to avoid implying an individual is either a man or a woman, and that to do this we are sometimes permitted to violate rules of number agreement which otherwise we must respect. If we are using Pitjantjatjara, special rules apply about what kinds of things we can disclose to which categories of person and our relationship with them, their age and gender, and with which kinds of person we can speak directly or must speak indirectly to. If we are using English, we must accept that a boy who falls from a tree can say "I broke my arm!" without implying that he intended to do this, which to a speaker of Hawaiian sounds distinctly strange. Why would you break your arm? 
These are only a minute number of the myriad ways in which languages operate a system of interpretation of the world as they accomplish mundane tasks and thereby embody a quotient of cultural diversity. This stock of cultural diversity in languages is not inert. Instead it consists of miniperformances of the values and routines of the language in question, not things that can be known, though this knowledge is available to us as well. Instead, what is most powerful about the cultural diversity perceived through multilingualism is that it involves something we do, that is, it involves differences that are performed, in which speakers are required to enact distinctive semiotic assumptions and conversational practices as routine and normal. We cannot communicate effectively if we constantly struggle against the grammatical, lexical and semantic resources a given language makes available to us as its users.

One way that language differences have been formulated theoretically is in the construct of linguistic relativism. Linguistic relativism is a scientific claim that different languages predispose their users to think differently, and that this bias resides in grammatical and lexical structures. The relativity thesis is a very ancient insight that has been formulated in different ways at different times. Some 70 years ago this ancient claim was famously formulated in the Sapir-Whorf hypothesis, named for two North American linguistic anthropologists, the Canadian Edward Sapir and the American Benjamin Lee Whorf, who proposed that different languages either influence thinking processes in unique ways (the weak version) or that they determine thinking (the strong version). Unable to be tested reliably until recent times, the Sapir-Whorf hypothesis has benefited from recent empirical research that has thrown new light on what had become a vexed issue of relativism and perspective in language.

A recent review of research on this hypothesis finds a growing corpus of studies steadily accumulating empirical demonstrations of stable and significant linguistic relativism. Three kinds of relativity can now be discerned. The first is "semiotic relativity, or how the use of a symbolic system affects thought"; the second is "linguistic relativity, or how speakers of different languages think differently when speaking" and the third is "discursive relativity, or how speakers of different discourses (across languages or in the same languages) have different cultural worldviews" (Kramsch 2004, pp.241, 244, 247).

In the light of the pervasive presence of differences of perspective across these layers of communication the project of support for cultural diversity can be more confidently and intimately associated with multilingualism.

\section{Shared communication}

A classic work of Asian language planning theory and practice, S. Takdir Alisjahbana's Language planning for modernisation (1976), surveys the history of Indonesian and Malaysian language policymaking and the circumstances, theory and options available to these societies. While reflecting on the post-colonial realities of Malaysia and Indonesia the writer discusses the emergence of nation-states in Europe and ascribes decisive importance to this development as far as the fate and destiny of multilingualism is concerned. According to Alisjahbana the elevation of national cultures and the national languages within them was critical to the fate of all languages in these societies. As a key architect of modern Indonesian his analysis and reflections apply to the extensive multilingualism of the Indonesian archipelago but have a much wider resonance.

Alisjahbana's analysis focuses particularly on the role played by cultural patterns that gained the authority of the nation-state. Nation-states favour particular kinds of discourse and reasoning that reflect the specific narrative of the polity and come to form the expected values and behaviour within which vocabulary, discourse and practices of communication, no less than grammar, take shape and circulate throughout the population. In a 1964 lecture in Kuala Lumpur Alisjahbana foresaw the advent of globalising or universalising forces and their impact on multilingualism, and made a remarkable claim about globalisation and shared communication. According to this view:

The strong globalising and unifying tendencies of social and cultural life must also find their expression in the converging tendencies of modern languages ... modern languages are much nearer to each other than the relationship of languages in any epoch of history because of the growing globalisation of societies and the growing unity of the basic concepts of 
modern secular culture dominated by science, economics and technology. (Alisjahbana 1976, p.7)

Here we do not have only a depiction of the restriction of future space for cultural diversity through language extinction and the loss of unique world-views. This claim goes much further to argue that the large and major modern languages, even though they represent distinctive national traditions and benefit materially by state support in their independent and stable countries, will progressively converge towards each other in their deep meanings. Attributing this to what he calls the "arising world society", Alisjahbana predicts the convergence of world-views. The British theorist of nationalism, Ernest Gellner (1983), predicted a similar progressive convergence of broad meanings and notions of reality across different languages. According to Gellner, social, economic and ideological worlds progressively come to resemble each other so that differences will ultimately be restricted to surface level expression and surface communication while deeper meanings will become closer.

These are controversial formulations but increasingly we see the emergence of world systems in many jurisdictions as the management of cross-border trade, crime, pollution, travel and information and culture flows requires the forging of common or at least overlapping understandings of phenomena to permit collaborative management to take place between countries. One recent example is the production of internationally comparable statistics about children's literacy attainments and capabilities. Education ministries across the world are sensitive to international performance data and comparisons. As more data is produced about how literate Taiwanese young people are, how they count and perform other mathematical operations, what world knowledge they possess and how these assessed performances compare with peers in California, Australia, Japan and Germany, the more a shared language of expectations, concepts and comparisons emerges. Such international comparisons are an indicator of the progressive aggregation of the world into common and shared conceptualisations and are evidence for the kind of convergence that Alisjahbana and Gellner predicted. Education ministers in Sri Lanka and Norway, Botswana and Belgium, despite the incomparability of the social settings of their education systems are increasingly tied together in a network of generalisations, conceptualisations and categories that permit them to talk about their diverse fields of activity in shared ways.

However, there is potentially counter evidence in some reactions to globalisation by movements that stress localisation and regionalisation as a rejection of or response to global trends (Castles and Miller 2003; Giddens 1999; Grin 2003) and in the increasing hybridisation of languages of wider communication, and the important distinction between what languages as systems make available to speakers as meaning potentials and what meanings speakers actually make using the tools available to them. In light of these dynamics, language policies should aim to support languages in three broad categories, classified as three "i's": indigenous, immigrant and international languages. Credible language policy and planning need to respond to the express wishes of populations and therefore to act at the sub-national, intra-national and extra-national levels, implying in turn support for languages of local relevance and intimacy, for mobility and dispersed populations, and for international languages that offer portability and exchange. To attract the widest citizenship support, language policy and planning should encourage support for languages of common or wider communication along with the spread of universal literacy, but this goal should be matched by a complementary and strongly pursued commitment to the maintenance of local and regional cultural diversity by the validation of legitimate difference through multilingualism.

\section{Language policy}

This section describes the activity, types, agents, sites and notion of language policy.

\section{Planning categories and policy conversations}

For the most part we are used to thinking of language planning and policy as the province of the state. A long historical analysis of state language planning activity would show that the bulk of this action has been against rather than in favour of multilingualism.

This subsection considers the instruments of state action that have been used in the management of 
language in diverse societies, and argues that language policies to support multilingualism in society and plurilingualism among individuals are not technical or mechanistic protocols or formulae but are discourses in a kind of language policy-making that should accompany formal policy texts. Specifically, the discussion identifies four domains or spheres of language policy activity (sovereignty, jurisdiction, influence and behaviour) undertaken through four characteristic modes of participation: public texts (such as laws, regulations and planning); public discourse (statements, discussion and public attitudes); and performative action (that is, role model behaviour, what powerful and significant individuals, institutions and entities actually do in practice, which provides models for linguistic and cultural behaviour) and deliberative process (facilitated discussion of policy problems, problem clarification, strategic planning and implementation). All these are directed at one or more of six broad language planning purposes, discussed below.

We must avoid mechanistic and rationalist accounts of language planning as an activity entrusted to experts who exercise expert control over bodies of information and produce plans that are administered by others. Language in general and multilingualism in particular are problematical objects of policy-making. Because these issues are invested with emotional and ideological power and with cultural values effective language policy and planning require processes of deliberation, negotiation, problem definition and the ongoing participation of affected parties. This is not to deny a clear and important role for scholarship, expertise and experts. Data gathered to inform policy-making in deliberative processes can be crucial to clarify problematical issues, explore feasible alternative courses of action, institute reliable kinds of evaluation and monitoring, make valid calculations of the likely cost and consequences of alternative courses of action and generally to guide discussion. Language policy is a process linked to power and the distribution of resources, and therefore to political and economic interests, but it proceeds most smoothly when it can be undertaken systematically through processes of guided and technically informed deliberation.

The importance of multilingualism in education is informed by a distinction between three policy orientations, initially proposed by Ruiz (1984). In this formulation policies are seen to have an underlying orientation or ideology that regards multilingualism as a problem, as a right or as a resource. It is proposed that policies should be explicit about their ideological assumptions and commitments and further that ultimately the most productive of the three broad orientations identified by Ruiz is the resource orientation, but substantially modified so that multilingualism is seen as a resource in a wide variety of ways. Multilingualism is advocated as an intellectual resource, a cultural resource and a resource for active participatory citizenship, as well as a resource in economic and occupational terms and a resource in the advancements of human rights.

\section{Spheres of activity for language policy}

Language policy-making is for the most part undertaken within the sovereign powers of the state or its dependent agencies. However, even actions of resistance against state policy need to be understood within a wider framework of policy as an activity and policy as a conversation; the approach that is favoured here. Therefore, while the formal instantiation of language policy might most readily be identified in laws, regulations, rules, funding provisions and the administrative arrangements of state agencies, the relevant spheres of activity are much wider. The following four, modified from a recent discussion of Chinese language planning (Lo Bianco, 2007b), represent both the actors/agents and the domains or spheres of activity in which they act on language policy. Some of the typical kinds of activity they undertake in the spheres they control are also identified. These spheres are enacted through particular modes of participation, four of which are identified and discussed immediately below and typically for one or more of six broad purposes, which are discussed subsequently.

\section{Sovereignty}

A state or state authority acts within exclusive or pooled sovereignty across a series of jurisdictions. This is typically authoritative action involving the distribution of resources and the designation of roles and statuses. The modality is usually laws, rules and sanctionable regulations.

\section{Jurisdiction}

An authoritative agency or public institution that has a remit over a field or domain legitimately pursues language planning within that field or domain. The modality is often via responses to commissioned reports or internal documents, and other public texts such as press releases and public 
announcements concerning resource allocations.

Influence

Influential individuals (whether by expertise, power, celebrity or strategic position) or influential agencies convert public credibility, material power or diverse kinds of cultural capital into influence that they exercise over patterns of language use in multilingual settings or preferred meanings, values or styles of language use within single languages.

\section{Behaviour}

A community of language users, singly or in association with supporters and experts, organises its communicative expression in various ways to retain or recover language use inter-generationally or to reject or accommodate the intended policy messages from sovereign action or from institutional or administrative action. Often linguistic behaviour involves resistance or struggle against forces from outside that erode the capacity of the community to pass on its language through processes of intimacy or socialisation direct to new generations or to newcomers or to adopt new norms, expressions or meanings that respond to its internal ideological or behavioural norms.

Language planning is the activity of implementing a language policy, an activity which might occur in one or more of the spheres above. However, while the sovereignty and jurisdictional domains frequently involve explicit promulgations of policy in the forms of laws or authoritative reports, the sphere of influence and behaviour tend to involve a kind of policy-making as practice, that is, social activity or behaviour rather than declarations, laws or formal statements.

\section{Modes of participation in language policy}

Three broad modes of participation in language policy and planning activity can be identified. These essentially constitute an ongoing conversation around language policy-making and depict the dynamic, iterative and dialogical character of the formulation of policy, its enactment and how policy is experienced and responded to. These modes of participation apply more or less across the six purposes which follow and in the four spheres indicated above.

\section{Public texts}

This is the most overt and declared mode, and involves laws, regulations and formal operations of planning and implementation. The procedures for the preparation of public texts usually demand political legitimacy and control of institutional resources.

\section{Public discourse}

This refers to statements, discussion and public attitudes that accompany or respond to, or precede public texts. Discourse is an essential component of language planning because formal declarations are not always implemented and they sometimes involve political rhetoric, interests and ideologies. In the discourse domain these are subjected to critique and analysis and represent the space for public debate and understanding, appreciation and adoption, dissemination or contest and resistance against promulgated texts of policy and the formulation of alternative courses of action.

\section{Performative action}

This refers to behaviour, both role model behaviour and subversive, transgressive and undermining behaviour. This is essentially about what powerful and significant individuals, institutions and entities, collectivities and communities actually do in their communicative practice and in so doing provide models for linguistic and cultural emulation. Performative action is also a kind of covert language policy-making when it transgresses what authoritative individuals model or proclaim or what public texts mandate.

\section{Deliberative process}

Facilitated deliberation is a way of doing language policy and planning that combines the role of experts and their expertise, affected populations as representatives and people with jurisdictional authority over a particular domain of language policy. Its general aim is to produce collectively agreed courses of action to solve language problems. 


\section{Purposes of language planning activity}

Six broad actions or purposes of language planning activity are briefly described below. These are the broad objective or aims pursued by the four modes of participation in language policymaking, which characterise how activity in the four spheres or domains of language policy-making is undertaken. The following six main purposes of language planning involve actions that determine the status of languages, aspects of their corpus, aspects of learning and acquisition, the domains of usage, the esteem or prestige attached to language and the discourse and attitudes that surround given languages or varieties, or issues such as multilingualism.

\section{Actions that formalise or elevate the status of languages}

The formal status of a language is reflected in its legal standing and public functions envisaged by the constitutional arrangements in particular countries. The formal status of a language is typically ascribed via public texts such as constitutional provisions and is undertaken in the realm of sovereignty of state authorities. However, sub-national groupings such as regions or provinces operating under autonomous statutes can modify, elaborate or even contradict public texts and laws issued by authorities with overlapping sovereignty. Supra-national groupings, such as the European Union can also attribute a formal status to languages. This occurred in 1992 when, in collaboration with the Council of Europe, the European Charter of Regional and Minority Languages (ECRML) was produced and promulgated to European states, the same states which had in the heyday of national sovereignty suppressed these same languages (ECRML, 1992). The Association of Southeast Asian Nations (ASEAN) has designated English as its sole operating language, but this is a jurisdictional, rather than a sovereign, sphere of activity and applies only to the operating arrangements of the ASEAN. The African Union, when it was known as the Organisation of African States, issued a Language Plan, but because of its lack of both sovereignty and jurisdiction the Plan could not be implemented.

Many countries have both exclusive sovereignty and jurisdiction and include statements in their national constitutions naming the official language and setting out the status of other languages. This legal recognition can be very simple, such as the formal nomination of the designated official language. More elaborate statements can specify the roles of languages or prescribe the functions they may have and the jurisdictional domains within which they can operate. Constitutional provisions are located along a continuum of pragmatic to symbolic characteristics, with a wide-ranging variety of mechanisms for implementation, from strongly binding provisions to weak symbolism. The instruments for effective language policy cannot rely solely on legal provision as constitutional support for languages cannot be implemented.

Transnational intergovernmental organisations and nation-states provide a diverse range of examples of constitutional provision for languages. For the most part these are public texts in the sphere of sovereignty. Sometimes the policy form is based on influence and occasionally on other kinds of language policy models. The South African Constitution recognises 11 languages: Afrikaans, English, Ndebele, Northern Sotho, Southern Sotho, Swati, Tsonga, Tswana, Venda, Xhosa and Zulu. The Australian Constitution makes no mention of an official language but the monolingual operations of its institutions sanction only English. Ethiopian constitutional provisions are closely tied to a transfer of administrative authority, and therefore jurisdiction, to a range of numbered administrative regions called kilil, which are in turn mostly language-based and which have considerable language autonomy. Sri Lanka's Constitution has been amended several times and contains both clear and ambiguous language provisions. These need to be interpreted with the assistance of other public texts of language issued in negotiations on the social and institutional roles envisaged for different languages. At the time of writing, in Sri Lanka Sinhala and Tamil are described as both national and official languages, while English is designated as being neither and is instead placed in the undefined category of a "link language".

All sovereign countries make use of the legal provisions available to them under the administrative scope provided for or limited by their own constitution to organise their national linguistic resources. Canada recognises two official languages and, although English is economically and socially dominant, English and French enjoy equal legal status. However, a series of laws in the Province of Quebec have modified the application of this legal equality in some of its domains, such as the 
selection of immigrants, public signage and education. Belgium's Constitution recognises French and Dutch in different parts of the country, though language usage is based on local variants of these languages, and has separate laws that recognise German in a small area in the east, and the national capital Brussels, is bilingual. The Indian Constitution recognises Hindi and English as having national official status, but schedules another 13 languages in particular states and additionally recognises a large number of minority languages for sub-national, regional or other jurisdictionally defined functions. In some countries history, economic and political forces substitute for a formal designation of the official status of languages. An example of this is the USA, where some 22 states have declared English to be the official language, while others have declared it is English plus another language (Hawaii recognises English and Hawaiian), while most, including the Federal government, do not recognise any language at all. In 1990, however, the US Congress adopted the Native American Languages Act, providing formal, jurisdictional but non-constitutional recognition and support to Native American languages.

\section{Actions that modify the corpus of a language}

Policy actions to impact on the status of languages are usually undertaken by politicians and policymakers who produce public texts, such as laws, constitutional provisions and authoritative reports, as described above. Actions that modify the corpus of a language are typically entrusted to specialist professional linguists in collaboration with a community of speakers; though this often also requires normal policy processes for approval. Corpus planning involves modifications to the internal meaning making resources of a language. This can include devising an orthographic system for a language that lacks a writing system or modifying an existing orthography. Extensions to the terminological range of languages, including standardising translation, codifying expression and disseminating the use and adoption of new norms are part of corpus planning activity.

The work of linguists to develop writing systems for indigenous languages or to develop terminology and expressions for both indigenous and national languages is an ongoing endeavour. Dictionary writing and creating prestigious literature also impact on the corpus of a language, and ideological and social movements can make language an object of their attention. Major changes to English expression since the 1970s are a result of the success of feminist agitation for the removal of masculine orientations in both written and spoken English. Corpus change occurs through both a deliberate, conscious processes of planning and through the adjustment of language to social trends, changes of values, technological innovation and scientific progress. All languages are constantly evolving to accommodate new information and changed meanings.

A major objective of corpus planning for small indigenous languages has been to enhance the prospects of intergenerational language maintenance or to reverse a language shift (Fishman 2001) and a key aim is to ensure that public education or secondary socialisation can support intra-family language transfer. For use in public education, corpus work focuses on changing the curriculum, expanding terminology, producing literature, developing scripts and orthography and disseminating these technical changes so they are adopted by language users. Sovereign and jurisdictional domains are rarely involved in corpus policy work except in repressive states that explicitly seek to extinguish minority languages by restricting the domains in which they can be used. Performative action by significant individuals within the community of speakers is a far more potent mode of language policy and planning than texts, laws or regulations.

\section{Actions that promote the learning of languages and the acquisition of literacy}

This occurs within the remit of public education institutions. Often, this kind of action occurs when a curriculum is implemented, rather than in overarching policies designed to promote the acquisition of a language or the expansion of literacy. A variety of agents are involved in this activity through a process involving interaction between experts, researchers, curriculum writers, assessment agencies, credentialing authorities and learners and their families.

As far as literacy is concerned, this is a domain in which there is extensive involvement of nongovernment agencies in developing countries and in which aid and assistance programmes of international organisations play a central role. 
Since the early 1990s and the emergence of human capital theories of education, developed countries have focused major energies on increasing standards and levels of literacy in schools in the belief that the more competitive economies are those that invest in raising the human capital skills of their workforces. Human rights thinking, and goals to improve health, rural development and social progress, particularly for marginalised groups, the poor and rural women have motivated the bulk of literacy campaigns in developing countries.

This kind of language planning is relatively free of public texts, laws and sovereignty provisions of governments but is highly dependent on effective administrative action and the technical skills of teachers, teacher educators and administrators.

Foreign language teaching, which is typically within the exclusive jurisdiction of education ministries but is sometimes elevated to prominence in national language policies also belongs in this category of actions. There have classically been several types of foreign language teaching policies, reflecting social hierarchies, positions and interests. Social elites have favoured the acquisition of prestigious languages, especially the languages of admired cultural or intellectual traditions. Authorities involved in planning economic and human capital development and national security agencies have favoured the acquisition of languages that are strategically important for trade, diplomacy, security or foreign relations. Religiously oriented curricula, or movements have favoured the acquisition of literacy less often than the acquisition of spoken skills in the languages of sacred texts that are associated with the canon of belief at the heart of the religious tradition.

\section{Actions that extend the domains and usage of a language}

This is a more recently identified purpose of language planning activity. It describes action taken to extend the settings and domains in which a language is spoken. Expanding the use of a language is seen to make that language stronger and longer lasting. An example is the work of the Welsh Language Board in Wales. In recent years status planning has given Welsh more formal recognition in the public texts of the UK and political devolution has transferred greater levels of administrative jurisdiction to Wales from the UK government. Empowered by such measures, but also independently of them and deriving from a sense of cultural recovery and the retention of the distinctive language of Wales, a wide range of language policy and planning activities are under way to strengthen Welsh. These moves have had considerable success and what used to be a seriously endangered language today appears to be stronger.

Using a language in the domain of intimacy (child-rearing practices) and early socialisation (primary schooling) means that more young children are being raised speaking it. One kind of usage planning has been to encourage mothers of newborn babies to bring up their children in Welsh and at the time or writing the number of infants speaking it has increased noticeably. Usage planning depends on significant individuals behaving linguistically in supportive ways. Performative action that sustains the language's desirability and encourages positive identification with it are crucial devices in this kind of language policy and planning. Usage planning requires integrated action to modify communication practices across business firms, broadcasting and publicity industries, employment practices and sporting and recreational activities to create space for the use of the target language. Usage planning in the Spanish region of Catalonia has also been successful, one instance being the participation of shopkeepers who cooperated to encourage consumers, with a special focus on young people, to prefer interaction in Catalan in daily life and thereby extend the perceived utility of the language. As a result of many such measures Catalan is today a more vibrant language than it was a few decades ago.

\section{Actions that elevate the prestige and esteem of a language}

The purpose of this language planning action is for writers and others with social prestige to try to raise the reputation of a language. Historically, esteem has been conferred on languages in proportion to the quality and extent of important works of literature in them. Dialectal forms of standardised languages have benefited over time by a change in the esteem, regard or informal status which they enjoy due to the standing of authoritative poets, novelists or scientists whose works were first produced in that form and which contributed to its standardisation. Official academies 
support literature in the national language, especially if it is a language that has been suppressed in the past, and these academies aim to bring about a change in its informal status. As people come to admire the language and feel that it is capable of expressing significant thoughts or that it is the repository of an important heritage in its literature or intellectual traditions, the expectation that the language can support state functions and individual language choices expands.

However, literature is far from being the only source or origin of prestige. Styles of speech that are attractive because they disrupt traditional notions of correctness or formal rules of appropriateness are also dependent on esteem in the subjective judgment of groups that desire and value such linguistic transgression. Esteem and prestige refer to cultural capital, the material and symbolic resources that a user of a language, style, dialect or variety of a language is able to command in a given audience.

Different audiences value forms of expression appropriate to the particular domain, and the behaviour and goals expected of the given audience. As a result, subversive modes of talk, music and performance genres of diverse kinds and multi-modal digital communications that create community and identity all confer esteem on a particular mode of expression.

\section{Actions that modify the discourse and attitudes towards a language}

This is perhaps the most controversial kind of language policy and planning - indeed, some would dispute whether it can be considered language planning at all. It depends more on the sphere of influence and performative action than on jurisdiction or sovereignty. Essentially, this refers to modifying or reinforcing a world-view by persuasive talk or writing. Discourse planning has a range of meanings that include training people to develop persuasive ways to express themselves so that they can participate in society and accomplish their goals by effective use of written or oral communication. Discourse planning, in its worst sense, means propaganda or brain washing.

We can see discourse planning in action when advertisers try to persuade customers to purchase what they want them to buy by singing their jingles or when political parties try to persuade citizens that their way of thinking is the only right one. Political spin is pure discourse planning; an attempt to change expected meanings in words to make the message of a particular individual or political ideology prevail over alternatives. In these examples, the language used tries to block out alternative understandings or meanings so that the thinking process of an individual reflects what a powerful outsider desires.

Discourse planning is part of all other kinds of language policy work. Action to support multilingualism in language policy and planning will require making use of arguments that are persuasive to multiple audiences. Comprehensive and explicit national language policy in multilingual societies should be promoted in the interests of traditional languages and multilingualism at the sub-national, intranational and extra-national levels; and that such action is feasible and beneficial to both minority communities and to mainstream populations. To achieve such goals will require language planners to persuade public administrators, education officials, government agents and other power-holders that it is in their interests as well as in the national benefit to invest in producing a comprehensive national policy. This is best done by focusing on the practical communication problems that societies face and producing evidence that comprehensive language planning can assist in solving communication problems.

\section{Goals, aspirations and ideologies}

\section{Unity, citizenship and communication}

Historically the principal goal of language policy has been the formation and strengthening of states. However, this goal can be pursued with dramatically different means. In the third century BC in two Asian contexts the connection between multiple languages and public governance achieved high levels of attention. India's only Buddhist emperor, Ashoka, pursued political unification via linguistic pluralism, while Qin Shi Huangdi, first emperor of a united China, pursued political unification via linguistic uniformity. Ashoka's conversion to Buddhism stimulated linguistic tolerance, while Qin Shi 
Huangdi selected a single standardised variety of writing (the Small Seal) and mandated its use, suppressing regional scripts (Ferguson 1996). These ancient precedents have modern manifestations, as India's Constitution continues Ashoka's pluralism while China's remarkably steadfast ancient practice of uniformity in script and writing permits communication across vast differences in spoken language.

In Europe, language planning has classically been a state enterprise aiming to forge national unity through communication in a single, standardised, literate language (Lo Bianco 2005). The emergence of transnational organisations, such as the Council of Europe and the European Union, has reinforced internal moves towards greater linguistic toleration and opened up support for minority languages that had been displaced in the process of nationalistic language planning (ECRML, 1992).

In a study of the implementation and effectiveness of Europe's minority and Regional Languages Charter Grin (2003) concludes that for minority languages to be used requires capacity, opportunity and desire. These principles engage the entire linguistic ecology: capacity and opportunity require knowledge of the language at a level of literacy that is useful in contemporary societies, public attitudes that permit and do not discourage use of the language and a desire on the part of speakers to continue to use it. Further, they require a partnership between the state, other authorities entrusted with the responsibility to do language policy work and speaker communities. Not all communities, and certainly not all social conditions, are conducive to the maintenance and continued use of minority languages. A cooperative approach in which minority language users, state institutions and private sector representatives collaborate is essential so that those attempting to revive or revitalise endangered languages work closely with both actual and potential language users. Grin stresses that language use cannot be mandated, and that top-down policies ignoring "the role of actors" (p.85), even if well-intentioned, often fail.

Language policies that support multilingualism, language learning and the reversal of language shift are an indispensable component of the long-term sustainability of cultural diversity. However, some cultural understanding, insight, perspective and appreciation do not depend on linguistic diversity, since through translation, direct encounter, imagination, narration, art, faith and other means it is possible to encounter cultural difference in an appreciative and rewarding way. Additionally, it is salutary to keep in mind that many people in history who have been proficient in multiple languages have been hostile either to cultural diversity or to particular cultural traditions and connections.

There is no necessary and inevitable connection between linguistic diversity, language learning and maintenance and having a positive disposition towards cultural difference in general. Much language learning is in any case restricted to the learning and teaching of languages of elite forms of cultural prestige, and fosters the learner's admiration of and integration in the cultural assumptions and practices of a particular, selected and valued cultural system. Invariably, this will be a national and official language of an elite first world society or the language of a powerful economic group.

While this kind of language learning is valuable and important it does not necessarily flow on into fostering more positive attitudes towards languages in general, especially not towards multilingualism or the languages of sub-national groups. This is why principles of intercultural awareness and worldmindedness should be introduced into all language education, so that learners can generalise beyond self-esteem and admiration for an esteemed Other to adopt a wider understanding of difference.

All language learning has the potential to bring to the attention of the learner the culturally particular ways in which knowledge is organised and valued, as well as distinct traditions of thought, belief and values and the unique histories of lived experience captured in specific languages. In this way, cultural diversity should aim to ensure that two broad kinds of language learning are promoted. The first refers to the widespread acquisition of languages that enhance the widest possible networks across nations, faiths and regional communication, and the second to widespread support for the maintenance and protection of language-based communities seeking to transmit to future generations intact languages of traditional communication.

These two principles, language learning for enhancing worldwide contact and communication and for fostering the intergenerational retention and maintenance of intact language and cultural systems are essential to any sustainable and serious investment in and exploration of cultural diversity. 
National education objectives typically make unity, citizenship and intra-national communication the first priorities of public investments in education. Supporting language minorities and multilingualism needs to be seen as complementary to such goals. Minority communities, like mainstream communities, desire economic and material progress for their children. It is critical that plans for the maintenance of minority languages acknowledge and treat seriously the aspiration for such progress just as the fallacy that this requires the sacrifice of distinctive languages and cultural traditions is exposed. This kind of discourse language planning must accompany all formal language policymaking of its maximal effect, and it should be conducted through the deliberative process of debate and discussion of policy objectives.

An argument commonly raised against language policies supporting multiple languages in schools is that not all community languages can be supported. Therefore, as it is difficult to make choices and some groups will be aggrieved or disadvantaged, it is preferable to choose a single prestigious foreign or international language, a trading language or to offer no language at all. There are many instances from all around the world showing the fallacy of these arguments. Firstly, school support for many languages is in fact undertaken in many parts of the world. Some of the school systems of Australia offer 47 languages, not necessarily all during normal school time. Some of this language teaching is supported by broadcasting, digital or after-hours community providers integrated into the examination and assessment system of the schools. Other languages are supported simply by being formally acknowledged in the mainstream school and are learned by students outside the school itself, thereby validating community efforts to maintain their languages. In many other national settings we see similar creative solutions to the challenges of multilingualism (García et al. 2006).

\section{Reviving and retaining minority languages}

There are two broad approaches to minority language revitalisation and maintenance, the ecological and the sociolinguistic, and two broad frameworks of advocacy, demands for political recognition as citizens and linguistic human rights. The language ecology approach focuses on the communicative context in which individual languages are enmeshed, the "work" they perform in the economy of labour of communication (Mühlhäusler, 1996). The sociolinguistic approach addresses more closely the functional specialisation of languages (Fishman 2001). The great variety of circumstances in which languages find themselves defies easy generalisation and some scholars (Walsh 2005) argue that it remains unclear why language revitalisation sometimes succeeds and in other instances fails. $\mathrm{He}$ does note, however, "what is clear is that the process is profoundly political". Traditional approaches to documenting and theorising about language revitalisation or reversing language shift, owe their conceptual roots to the linguistic sciences and have tended to neglect economic realities (rewards and punishments) and political context (interests, the permeability of social arrangements, deliberation, policy and social repression or openness). Language revitalisation is always a situated practice in which the specific historical configurations that apply to this or that language in this or that socio-cultural, economic, political and historical circumstances shape what is possible. Most important for language revitalisation approaches is to incorporate a theory of interests, a corrective derived from recent attention to the work of critical sociologists, such as the insights of Pierre Bourdieu (1991).

One generalisable point, however, is the need for communication across the interests of minority and majority communities. In this respect, it is interesting that the language ecology movement argues that mono-cultures of the mind are as limiting and self-defeating as natural mono-cultures in biology and therefore argues that maintaining small languages is the interest of everybody, members of majority as well as minority communities. The belief that a variety of life forms is essential for biological survival has a parallel in human societies and adds to the arguments for supporting small languages based on the human rights of the speakers to continue to develop and enjoy their cultures and languages and to an improved education for their children.

In some respects, however, wider changes from globalisation recreate some conditions that typified human communities of the world before the development of nation-states. Supra-national governance is not unlike the dynastic and religious governance of this era, which permitted immense local diversity within overarching structures of belonging.

Language policies themselves, according to studies conducted by Tyler (2001) on their implementation, often succeed only if they are perceived to be procedurally fair and defer to the aims 
of the policy on the basis of consultative procedures which comprise them.

In Can threatened languages be saved? Joshua Fishman (2001) considers the obstacles that face efforts to revitalise minority languages on the basis of a review of an eight-point scale of vitality and language revitalisation over a ten-year period from diverse parts of the world. He reaches the broad conclusion that language loss is a late-order form of cultural loss, a phenomenon of already-advanced processes of cultural attrition. Rival identities deriving from outside the home and ethno-cultural context and language have already come to substitute for the position previously occupied by the endangered language. This state of eroded language identities means that advocates of language maintenance can be perceived as being in competition with the culture and instrumental value represented by the replacing language. Given that replacing languages are often languages of greater economic opportunity and social modernity, this makes advocates of language maintenance appear to be opposed to social mobility and therefore as parochial and anti-modern.

Compounding these already formidable difficulties is the complication that stable maintenance of small or minority languages over several generations requires communities to differentiate themselves to some extent socially and institutionally from the surrounding mainstream society. The prevailing ethos of social participation, especially in the economy and national institutions, means that any kind of distinctiveness can be perceived to be undermining social cohesion. The minority language functions that are retained via such differentiation require constant reinforcement. The result of these forces is that cultural separation or economic disadvantage tend to provoke negative responses from native elements of the nation, and provoke the adoption of state policies that stress the incorporation of all citizens into the regimes and values of an overarching national culture. Under these circumstances, policies that advocate the reversal of language shift may be rejected because they are characterised as undermining national unity and cohesion, or because they reflect the interests of older generations who are backward-looking and parochial when younger people prefer to integrate into the wider society of which they are a part.

From the point of view of colonised and marginalised populations, a policy for language support must integrate awareness, knowledge and relationships. Awareness refers to changes in consciousness among the speakers of the languages, policies to invigorate and value local stocks of knowledge and the genres that language knowledge is expressed in, as well as reinvigorated and living human relationships (Fettes 1997). Critical awareness is an instance of discourse language planning, and means contesting prejudice against minority language use vis-à-vis the replacing languages. Local "knowledges" is a concept that involves reinvigorating local, intra-family and intra-community usefunctions for threatened languages. Essentially this means finding spaces in the daily lives of communities and families in which the minority language is the expected, natural and exclusive medium of conducting at least some of the differentiated affairs of life. In turn this involves proficiencies in culturally appropriate functions. Living relationships involve children and adults (separately and in interaction) in recreating intact discourses in the language.

The first of these criteria, critical awareness, aims to contest the effects of negative characterisations of the heritage language by the dominant social and linguistic milieu. Beginning the process of language revitalisation with critical awareness recognises that inherited beliefs shape language practice with the language-maintenance eroding effects of negative attitudes seen as a kind of language planning. Seeing policy in this way means seeing the performance in discourse of an otherwise implicit but very real and powerful policy. In relation to threatened languages, the policy is usually unnamed and resides in the operation of prevailing social, economic and political arrangements. If named, such a policy would declare its ambition of provoking the attrition and loss of minority languages in the interests of a simplified mono-lingual polity. Quite often such undeclared policies that are the result of the operation of attitudes and beliefs from the past, even of habit and usage, contradict a formal policy declaration in the present aimed at the of revitalisation minority language. We can see prevailing attitudes, therefore, as a kind of past policy, one that is continually enacted and performed. This means that past accommodations on the relative worth of different languages, what language it is appropriate to use, when and with whom, once established, perhaps explicitly, become subsumed into the practices and habits of ordinary language use and are performed through ordinary linguistic transactions. When advocacy for intergenerational language maintenance is criticised, dismissed or repudiated as "sedition" or "parochialism", the unconscious and backgrounded policy intent is recreated and elevated to consciousness, displayed and performed, surfacing from its unnoticed, taken for granted state, to do its work. 
Language planning for cultural diversity should be understood as a situated practice, meaning that what counts as the most appropriate or most effective intervention to support minority languages is not identical in all settings. The balance of measures required in each case often makes sense only in the context of specific circumstances rather than being portable across settings and contexts.

\section{Culture, cognition and difference}

The school is often considered the primary site where the fortunes of endangered languages are played out, despite the fact that a long history of socio-linguistic research shows that schools, as the eminent sociolinguist Joshua Fishman observed in the 1970s, can be unreliable allies of language maintenance. The literature on bilingual education refers to three types of target audiences: (a) immigrant groups whose languages differ from the language in which public education is conducted; (b) indigenous minorities in New World settings or regional minorities (autochthonous populations) in Old World settings and (c) immersion language education for majority populations, usually in prestigious foreign languages.

The research evidence on bilingualism and early bilingualism now supports a broad and clear consensus on the cognitive and social advantages of knowing and learning in and through two languages. However, for much of the previous three decades there has been considerable controversy surrounding the educational and cognitive effects of dual language study, and claims are still commonly heard that minority children may suffer from semi-lingual- ism, a deformed kind of cognitive functioning. Research evidence and reasoning have traversed through three main stages in considering the relation of thought and bilingualism. In the first, early bilingualism was seen to have predictably negative effects on intellectual functioning. This was followed by a period of doubt, discussing bilingualism mostly as having no distinctive impact on intellectual functioning. Today, replicated research demonstrates reliably that precocious and high-level bilingualism correlates consistently with enhanced intellectual functioning and makes distinctive positive contributions to cognitive attainments.

Most early studies suffered from what would today be judged weak methods of research design and analysis. With reflection on research instruments and the removal of biases in research design and of deficiencies in variable control, research came to control more tightly for intelligence, social background and other significant variables. As a result, academic performance differences previously attributed to bilingualism were found to be more readily accounted for by other criteria and, as early studies paved the way for more careful and systematic research designs, repeated positive correlations between bilingualism and intellectual functioning were consistently identified and ultimately traced to the effect of bilingualism. In educational settings a key hypothesis proposed to explain more positive results is linguistic interdependence, associated with Cummins (2000), for which substantial confirmatory evidence is now available. Linguistic interdependence builds on longstanding awareness of differences between mundane and academic language uses and a sense that it is implausible that the two languages of a bilingual speaker are neurologically compartmentalised. The most common practical assumption about second language learning is maximum exposure, that is, that the more time spent studying the language the greater will be the level of proficiency attained. By contrast linguistic interdependence posits an "additive bilingual enrichment principle" (Cummins 2000, p.175), meaning essentially that the academic achievements 
TABLE 1. Three basic models of content second language teaching

\begin{tabular}{lll}
\hline Model & \multicolumn{1}{c}{ Learners } & \multicolumn{1}{c}{ Method } \\
\hline Bilingual education & Immigrant and indigenous children in & Maintaining minority language and learning \\
& X-nation & X as L2 \\
& X-nation emigrant children in Y-place & Maintaining X as L1 and learning Y as L2 \\
Immersion education & X-speaking children in X-nation & Maintaining X as L1 and learning Y as L2 \\
& Y speaking children in Y. & Maintaining Y as L1 and learning X as L2 \\
Foreign language teaching & $X$ and Y children learning language A & FL learning or immersion \\
\hline
\end{tabular}

Notes: FL, foreign language; L1, native language; L2, second language.

of bilingual children are tied to the cognitive relations between first language skill and second language performance. Bilingual education programmes are mostly directed at immigrant and indigenous children who are trying to maintain their first language, such as children who speak a minority or regional language at home and who learn the mainstream language in school. The pathway to bilingualism for these children is via the maintenance of the first language and new learning of the second, national language. The situation for majority children is typically different. In an immersion programme they would be learning bilingually by gaining a second language, such as English. In this model of immersion education, a second language is used to teach subjects for children speaking majority languages in their home countries. For indigenous minorities or immigrant children, the bilingual programme consists of learning in their first language and the mainstream language as their second language.

We see from Table 1 that bilingual education is typically directed at minority children, whether they are immigrants or from a regional or indigenous minority. This usually means that their first language is a home language that is rarely supported in the wider community and is often one that children struggle to maintain. By contrast, immersion content teaching is a strategy to teach a prestigious language. The difference between immersion and bilingual programmes is not so much about what happens in the school but what happens outside of the school. The content and prestige carried by the languages is different. But maintaining minority languages is not constituted so positively. The effort, time and resources needed are constantly questioned. This is the situation for children of minority language backgrounds who learn a second language as their main school language but much of whose communication and basic thinking skills have been developed in their first language. Their higher-order thinking skills, however, are in their second language because that is the language of education in their country. Over time this means that the second language comes to challenge and probably replace the first language.

Language policies can exist in the laws and regulations of a multilingual society but its informal communication practices and economic and social pressures can influence the fortunes of its languages. Overt, explicit and formal language policies that support multilingualism will not, on their own, achieve intergenerational language maintenance, nor will they on their own sustain the vitality of multilingual communities if social, economic and symbolic factors advantage dominant languages and promote language shift.

Favourable language planning will not necessarily enhance the linguistic vitality and intergenerational retention of minority languages if the social, cultural, economic and political messages of a society promote linguistic uniformity or if the economic arrangements of the society penalise minority communities and promote language shift. Language communication exists in a complex ecology in which multiple modes of communication co-exist and share the communicative load of speakers' needs. Languages serve multiple and interacting needs, such as conveying messages, coordinating actions, sharing experience, structuring collective and individual memory and advancing social affiliation and solidarity. However, in multilingual settings, not all individuals are plurilingual and even those who are never equally proficient in all their language codes across all domains of usage. Instead plurilingual individuals in multilingual settings deploy a repertoire of variable skills in spoken and written languages, including partial and temporary proficiencies and dialects and expressive styles across diverse functional areas of communication. 


\section{Effects of globalisation}

\section{Contradictory patterns and trends}

Under the conditions produced by the more rapid integration of geopolitical entities, especially of the more tightly linked urban zones of the twenty-first century, it is no longer possible to confine language policy and planning actions to the realm of sovereign, bounded and autonomous states. Everywhere education systems, policies and institutions are being transformed by "the widening, deepening and speeding up of worldwide interconnectedness" (Held et al. 1999, p.2) and, although it is often regarded as a recent phenomenon, it is more likely that such globalism has been under way for a long period of time (Hopkins 2002). The tighter and greater integration of urban zones, and increasingly of all inhabited spaces, combines political and economic change with cultural change (Suarez-Orozco and Baolian Qin-Hilliard 2004). Continuously extending networks based on travel, mobile phones, broadband Internet and other information and communication technologies are creating new forms of human association of unprecedented scale and flexibility, spanning cities and nations with varied cultures and hybrid kinds of identity and levels of economic development.

Globalisation is nuanced according to locality (area, nation, region, world), language(s) of use, culture and social organisation. It plays out differently in different kinds of institution and in nations with differing economic capacities and cultural and linguistic starting points. At the same time as globalisation has foregrounded an expanding role of English, it has also encouraged more plural and hybrid approaches to English, problematised certain national language policies, brought to the fore stronger regional dialects, often crossing national borders, such as Bangla (Bengali) in Bangladesh and India and created new needs for language plurality in many countries, such as skills in Mandarin Chinese. Language policy is often central to global competence and is a live issue in all nations. The discussion of how to support multilingualism must incorporate a more sophisticated understanding of these issues, going well beyond the disciplinary knowledge and concepts of the linguistic sciences. Several overarching patterns are discernable in the effects of globalisation in relation to communication. Some of these are listed below.

- Instrumentalism in communication is producing a transnational generic English, standardised syntactically, but divergent phonologically and lexically, marking English-knowing elite identities while more variant local Englishes, often characterised by code-switching, "crossing" and other kinds of cultural pragmatics are used by non-elite but upwardly mobile groups. Although other languages of wider communication are strong and some are growing rapidly, the unique position that English appears to have occupied in the communication plans of many nations, that of the convenient vehicle for use in non-native to non-native English communication, is unprecedented in human communication.

- There are a few reactive movements that focus on identity-infused localism posing an antiEnglish programme. However, sub-national agitation for language rights is more often directed at national languages than at the global functions of English.

- Technological innovations make it possible that some kinds of communication will be mediated electronically, but not in written form, such as voice-instructed computers permitting the storage, organisation and retrieval of information though non-literacy based commands. Other technological innovations hold out the prospect that tone languages and character-based languages may not need to experiment with romanisation or alphabetisation.

- Technological innovations also hold out the possibility that small, dispersed and mobile communities will be able to facilitate effective intergenerational first-language communication in indigenous, and immigrant, languages.

- A vast contraction is taking place in the domains of many languages, including extensive language extinction, at the same time as hybrid or mixed kinds of language add to the stock of human language diversity.

Some of these tendencies are contradictory and others are uncertain, but the effects of globalisation are multi-directional and appear to stimulate both attraction and reaction to cultural influences from 
outside local settings in different life domains and different parts of the world at different times, so that both localism and regionalism arise in response to moves towards global connections.

\section{Scripts, technology, and literacy}

Along with dialects and standardisation of dialects into national, or sub-national, but officialised functions, scripts merit recognition in the discussion of language and cultural diversity. This is especially true given the massive attention that written language planning and policy-making occupies in Asia, in the character-based languages of East Asia and the multi-script environments of the Indian sub-continent.

An analysis of language trends in Europe would contain very little attention to issues which, in East Asia at least, have been major, even massive, preoccupations of language policy and planning: script and writing. Gottlieb and Chen (2001, p.5) note that "reform of script and written language is usually what first springs to the mind of language planners and the general public" in the patterns of intersections between language and public action. For more than three decades from 1954 the national official institution for language in mainland China was called the Chinese Committee on Script Reform (Zhongguo wenzi gaige weiyuanhui), only being renamed the State Language and Script Commission (Guojia yuyan wenzi gongzuo weiyuan-hui) in 1986. The 2001 Common Language Law is remarkable in this respect, in that issues of script permeate virtually all articles of the law (Rohsenow 2004, pp. 41-43).

Similarly, standardisation is also of central importance in the patterns of language action we find in Korea and Japan. Each setting, is distinguished by the particularities of its histories and circumstances. Korea is experiencing a delicate oscillation between convergence and divergence between South and North (Song 2001). These patterns of convergence and divergence are not new in the relations among states with shared nationality but divided politics, but in recent decades in South Korea they have been intensified by the precarious economic state of North Korea.

The Seoul dialect was designated the national standard more than 600 years ago. In 1936 the Korean Language Society (Hankul Hakhoi) formalised this status specifying that educated middle-class speakers were the standardising source. After the 1950s, in a major diverging move, the dialect of Pyongyang was allocated the function of setting norms and standards for the language in the North, marking political as well as linguistic divergence between the two countries. In South Korea the government has wavered from time to time on the role permitted to Chinese characters, alongside the alphabetic Hankul system developed in the fifteenth century whereas, like Vietnam (Lo Bianco 2001), North Korea initially stressed a mass literacy policy favouring Hankul by abolishing characters, but has moderated this stance since 1966, permitting the teaching of characters in schools but banning their use in the public media.

In Japan, as well as South Korea, economic development has been a motivating force in script debates in recent decades; in both cases animating moves for "rationalisation" and simplifying reforms, but conservative reactions have followed to restrict the scope and extent of such changes (Carroll 1997; Gottlieb 2001; Song 2001).

Future patterns will no doubt be influenced by the impact of electronic technologies, especially the digitisation of text production. What impact will there be on script policies based on the exigencies of handwriting as an esteemed cultural practice, an expressive art form, historically revered and sanctioned by close association with ancient values? Technology also requires cross-national standardisation rather than country-by-country norms. Efficient market globalisation requires common cross-national standards to handle computer-to-computer communication. Although electronic standards diverge among the character-using countries at present, Gottlieb and Chen (2001) report that since 1995 an ISO 1646 character code has been emerging and that Japan's 1995 adoption of a 20,902 character UNICODE suggests cross-national possibilities, despite the persistence of compatibility problems. Today, however, the real interest appears to have shifted towards the manifold promise of voice operations of machines, and especially of computing, and the emergent possibility of speech to writing protocols, promising a radical reshaping the ancient hierarchy between written and spoken language and their separation. What impact this innovation will have on spoken language pluralism is open to speculation but one possibility is the erosion of the formula that 
standardised writing is indispensible for intergenerational cultural survival.

\section{Global communication}

Separated by almost 10 years are two important studies of the exponential growth of English in the world today. David Graddol's first analysis in 1997 and, in 2006, English next. The latter study concludes that two billion people, a third of all people, could be engaged in learning English by 2015, while as many as three billion people or half the world's population could be speaking the language in a future time period. This shows that the world already has a de facto international auxiliary language, a language which Braj Kachru (2005) has described as "the only shared ... medium across the vast Asian region" (p.xv), the zone of the world where the bulk of its population lives.

What direct effects, beyond the general impact of economic globalisation, does the expansion of English to these immense levels imply for multilingualism? This is an impossible question to answer definitively. Some indicators might be found in the enhanced interest in languages other than English and the recovery of English dialects in English native-speaker societies, perhaps suggesting that the explosive growth of English worldwide does not obviate the need for communication forms more closely associated to place, locality and identity; or from the transactional uses to which English is restricted in other settings where it has taken root, suggesting that English in these settings performs only functional and instrumental roles. There is evidence that in some instances of language loss transfer away from minority languages is not necessarily towards English but towards other rival local languages. None of this can be other than highly generalised speculation. Global communication is actually regionalised, making a range of languages of wider communication relevant as a lingua franca in Africa, across Europe, Asia, the Americas and the Pacific. As a result, global communication will never be exclusively in English, though English does appear destined to continue its dominant role for a considerable period into the future. None of this obviates the overriding importance and justification for energetic language policy and planning to support multilingualism for cultural diversity.

\section{Concluding observations}

This article has been devoted to discussing language policies and multilingualism in the context and in the interests of retention of cultural diversity. This section makes broad proposals for deploying the methods and practice of language planning and language policy-making to advance the prospects of a more secure place for linguistic pluralism both within multilingual nation-states and across states and onto a transnational plane, as well as sub-nationally at the level of locality and region.

\section{Policies in support of cultural diversity}

UNESCO has been in the forefront of positioning multilingualism and language rights as central elements in cultural diversity. It is crucial for world agencies and prominent national, philanthropic, commercial and non-government agencies of all kinds to move now to the modelling of language policy and planning that will assist in realising these objectives in both pragmatic and symbolically significant ways. Given that effective language policy and planning is not a readily portable practice but one that responds to local situations and circumstances, the aim should be to avoid formulaic models and didactic modes of operating. Instead, deliberative forums aiming to clarify policy objectives and goals, and to encourage strategic alliances and cooperative action in favour of multilingualism and cultural diversity, require support in new countries such as Timor Leste and older independent nations across Africa and Asia that are characterised by demographic multilingualism.

The most powerful way to influence existing policies is to conduct evaluations of practice. Comparing actual practice against the aims that ministries of education and governments have set themselves invites the researcher and the policy-maker or a community of speakers to join a conversation about the aims of policy itself. In this way they can engage in discourse planning, shaping how people talk about the problems to be tackled in language education planning.

A second key way to influence policy is to develop strategic alliances across language interests. 
Typically this involves inviting people interested in teaching prestigious international languages to work alongside people concerned with sub-national minority, indigenous or immigrant language interests. It is useful to establish a deliberative policy mechanism for such collaboration so that they come together on the basis of broad principles that unite them and then engage in discussions about shared or overlapping concerns, points of difference and divergence, noting potential areas for collaboration. Deliberation processes also have the effect of raising awareness of the collective resource of language and can contribute to a more cohesive community taking action to foster its shared interests. This kind of collaboration is not always feasible or necessary but where it is it can prove very effective. This was the basis of the national language policy success in Australia during the 1980s and in post-apartheid South Africa. In both instances people with diverse language interests came together, learned from each other and developed shared goals for language planning.

Ultimately, language policy is a conversation; a conversation about the communicative abilities, rights and opportunities of a society. Developing such a conversation will be easier and more effective if the aim is to develop explicit, comprehensive and public national language statements in a collaborative and democratic endeavour.

There is no perfect, ideal model for a language policy or plan to support multilingualism in the interests of safeguarding cultural diversity. However, there are eight characteristics of optimal success:

Commence with first principles. Declare an interest and belief in supporting human development, social justice and language rights, without infringing on the rights of others affected by the policy itself.

Be explicit. Declare the intended achievements of the policy.

Articulate and coordinate the policy. Separate the policy domains into articulated sequences so that actions taken at one level, such as primary schooling, are responsively addressed at pre-primary and post-primary school levels. They should also be coordinated so that an action proposed in discrete areas or jurisdictions is joined up to its effects in other jurisdictions or areas of administration.

Be comprehensive. Address as many language interests and interest groups as possible to ensure procedural fairness and gain legitimacy.

Collaborate. Involve in direct and meaningful ways all affected parties whose consent and participation should be sought in the process of producing a policy, from first principles to implementation to evaluation and modification.

Aim for durable policies to achieve actions in the short and longer term.

Monitor, evaluate and modify the policy. Explicit and overt processes of review are important to retain procedural fairness, to be humble about objectives and to acknowledge that unintended or unjust consequences for some groups in the community can sometimes result from well-intentioned plans. Redress mistakes and alter course if improvements, change or modifications are required.

Countries today face considerable language challenges at three levels of application, the subnational, national and extra-national and each of these levels also involves categories of languages, including the indigenous, the immigrant and the international. It is nevertheless sometimes possible and necessary to develop a language policy that targets one or even none of these categories or that addresses only one of the levels of application.

\section{Modelling and sponsorship of effective language policies}

The field of language policy-making and language planning in general lacks a dedicated international institutional home. It would be valuable if there were at least an international agency concerned with documentation of the practice of language policy-making. Such a body could also explore ways to 
disseminate models and examples of effective language policy and planning. Even this process of documentation could help support the principles of language rights, social cohesion and effective communication and research and represent the beginnings of global monitoring and further elaboration of language policy. Given the recurring concern of nation-states for social cohesion and the confounding of monolingualism with the idea of communication, instances of how shared communication can accompany multilingualism should feature in an internationally sponsored programme devoted to supporting cultural diversity through multilingualism that is sensitive to the need for social mobility and cohesion within states.

\section{Research in support of cultural diversity}

\section{Cost-benefit analyses}

Parallel with the concern for social cohesion is a largely unwarranted or at least exaggerated concern about the financial costs associated with multilingualism in education. In addition to disseminating practices that support effective language planning, international agencies could compile a scholarly review of claims and counter-claims of the costs and benefits of multilingual service provision in education, health and rural and regional development. The analysis should identify hidden and longterm costs in all kinds of provision. Initially research should aim to identify the overall parameters of such analyses prior to engaging in public discussion about the refinement and further elaboration of the costs and benefits of such documentation. The costs and benefits that are claimed and that can be documented in various ways, should be identifies using conventional statistical measures and the testimonies, narratives and oral histories of social participants, including a special effort to address the actual costs of both monolingual and multilingual policies and their respective consequences for communication. These could include the industrial and occupational accidents caused through instructions that have been misunderstood because of poor literacy in the official language. Cultural, aesthetic, identity and social benefits that are not amenable to quantification should be included although they cannot be costed. Modes of delivery of multiple language programmes

Along with cost, administrative complexity is the most commonly cited reason given against multiple language provision in education settings. International agencies should compile wide-ranging documentation of diverse modes of multiple language delivery from various primary and secondary sources.

\section{Agencies for advancing multilingual policy}

There is a need for agencies to advance effective implementation, monitoring, review and improvements in multilingual governance and public policy. International agencies could usefully develop the preliminary schema by documenting existing agencies worldwide and documenting their characteristics, successes and shortcomings, with a view to preparing a model structure advocating this policy.

A research culture should pervade all agencies that advocate multilingual policies, with the proviso that the research is aimed at generating knowledge that can be applied to support the intergenerational maintenance and elaboration of endangered languages or to cultivate effective communication in multilingual societies. The research should not be designed for strictly academic purposes, but to implement and support multilingual policy and programmes. The research would address all spheres and types of activity in language policy and planning. Examples of such research spheres are:

Status:

documenting processes and effects of language status, both formal and informal

Corpus: $\quad$ research into the range of ways that grammatical, literary and script corpora can be determined

Acquisition: $\quad$ studies of the many forms of language transmission and teaching in various domains such as the home, the school, non-formal and post-compulsory education, recreational and vocational domains

Prestige and esteem: documentation of the ways that public regard and attitudes towards 
languages are produced

Usage: $\quad$ research into how patterns of use arise in different domains or settings

Discourse: $\quad$ research into the representation and image of languages and how these interact with other aspects of language planning.

The research would also be characterised by an orientation towards the continual documentation of improvements in language policies, the evaluation of practices and the feasibility of various courses of action.

\section{Policy-focused research}

In this area international agencies would stress the connection of expertise to application and to continual improvements in policy. Research would be connected to the implementation of policies and programmes for supporting endangered languages and advising public agencies on effective communication practices for serving multilingual populations. This focus would mean that typically they would commission research on an as required or ad hoc basis, collaborating with specialist outside delivery agencies in various fields, rather than conducting research in-house. This would aim to ensure that research is not abstract and removed from the needs of policy-making. Application is seen to be the critical task.

\section{Speaker-based governance}

While governance should be widespread among various interest groups and representatives of speaker stakeholders require a prominent voice, languages must be strengthened by reinforcing family, social and everyday contexts in which they are used and threatened. This community orientation would aim to ensure collaborative relations between communities of speakers and public authorities, NGOs, expert bodies and supportive networks internationally and extra-locally.

\section{Integrating functions}

Action to strengthen weakened languages is required on many fronts if they are to be saved. Thus, these bodies must try to balance knowledge range of relevant areas, including bottom-up and topdown policy directions.

\section{Education in support of cultural diversity}

Education is a critical domain for supporting languages and action on behalf of them, and in the interests of cultural diversity. Decades of study across the world have thrown light on how language teaching and learning can be made most effective. From North America, especially Canada, and Scandinavia a critical lesson that has been learned is that there is a significant difference between academic and conversational language. Children can appear to be fluent in a language quite quickly, sometimes in as little as 6-8 months. However, it takes on average 5-7 years for a minority child coming into a new system to reach academic levels in the main language of instruction. Bilingual programmes that are not maintained for 5 or more years do not make the most of the advantage they offer minority children. However, programmes lasting for 1 to 3 years are still valuable culturally, and for early language transition. Such programmes can ease the challenge of initial literacy and assist with making initial concepts in education clearer and more easily grasped by learners. Nevertheless, academically it is desirable to aim for a bilingual programme to continue for the longest possible time for learners to reap maximum intellectual benefit from them.

Hong Kong and Singapore have provided insight into the use of different scripts in education Chinese and English. Different writing systems make different literacy demands on learners. If subjects such as science and mathematics are taught in the language of the mainstream society, say Spanish in Peru, or English in New Zealand, it is important to give children the terms to be able to talk about those concepts in their mother tongue. The knowledge gained this way is transferable across languages but explicitly offering the discourse and vocabulary in both languages assists children to 
talk about their newly gained knowledge. So one of the lessons from Singapore and Hong Kong, where different scripts are part of the bilingual context is that an early start and continuous immersion is most effective in such situations.

From Europe research has pointed to how to produce conversational proficiency in a target language. The key is often to link in-school activity directly to out-of-school language use. If we can encourage children to be conversationally fluent in the target language, then they are able to read more. If they are able to read more, then they are able to improve their cognitive level. European programmes have also pioneered the notion of incorporating the teaching of a second language as a subject into an otherwise immersion or bilingual based programme, so that before introducing the second language as a teaching medium it is taught explicitly as a subject. This might take the form of some months of explicitly teaching French before teaching subjects in French. One result of this approach is that children in such immersion programmes can have better grammatical skills than counterparts who might be conversationally proficient but whose language use is not grammatically as accurate.

\section{Conclusion}

It has been argued that multilingualism is an inescapable and central element of cultural diversity, making a unique and irreplaceable contribution to human diversity. The long-term survival of a truly and extensively multilingual world is entirely compatible with a world of shared communication and interaction. However, the prospects of success of either or both aims, communication and difference, pluralism and engagement, interaction and cultural autonomy, is dependent on effective processes of language policy and planning.

\section{References}

Alisjahbana, T. S., 1976. Language planning for modernization: the case of Indonesian and Malaysian. The Hague: Mouton.

Anderson, B., 1991. Imagined communities. Reflections on the origins and spread of nationalism. Revised London and New York: Verso.

Bateson, G., 1979. Mind and nature: a necessary unity. New York: Dutton.

Beacco, J-C., 2007. From linguistic diversity to plurilingual education. Language Policy Division, Council of Europe, Strasbourg. Available at http://www.coe.int/t/dg4/linguistic/Source/Beacco_EN.pdf [28 May 2010]

Bourdieu, P., 1991. Language and symbolic power. Cambridge, MA: Harvard University Press.

Carroll, T., 1997. From script to speech: language policy in Japan in the 1980s and 1990s. Occasional Paper Series, 27, Oxford: Nissan Institute of Japanese Studies.

Castles, S. and Miller, M. J., 2003. The age of migration, international population movements in the modern world. 3rd edn. Basingstoke and New York: Palgrave Macmillan.

Cummins, J., 2000. Language, power and pedagogy. Clevedon: Multilingual Matters.

Diamond, J., 2001. Deaths of languages. Natural History, 110 (3), 30-38.

European Charter for Regional and Minority Languages(ECRML), 1992. European Charter for Regional and Minority Languages. Strasbourg: France. 5.XI.1992. Available at: http://conventions.coe.int/treaty/en/Treaties/Html/148.htm [27 May 2010].

Ferguson, C. A., 1996. Diglossia, word. In T. Huebner, ed, Socio-linguistic perspectives, papers on language in society 1959-1994, Charles A. Ferguson. Oxford Studies in Sociolinguistics. New York and Oxford: Oxford University Press, 25-40.

Fettes, M., 1997. Stabilising what?An ecological approach to language renewal. In: J. Reyhner, ed. Teaching indigenous languages. Flagstaff, AZ: Northern Arizona University, 301-318.

Fishman, J. A., ed. 2001. Can threatened languages be saved? Reversing language shift, revisited. Clevedon: Multilingual Matters.

Forgas, J. P., Williams,K.D. and Wheeler, L., 2001. The social mind: cognitive and motivational aspects of interpersonal behavior. Cambridge: Cambridge University Press.

García, O., Skutnabb-Kangas,T. and Torres Guzmán, M., eds. 2006. Imagining multilingual schools: language in education and glocalization. Clevedon: Multilingual Matters.

Gellner, E., 1983. Nations and nationalism. Oxford: Blackwell.

Giddens, A., 1999. Runaway world. London: Profile.

Gonzalez, A.B. and Bautista, L., 1986. Language surveys in the Philippines, 1966-1984. Vol.1. 
Manila: De La Salle University Press.

Gordon, R. G., ed. 2005. Ethnologue: languages of the world. 15th edn. Dallas, TX.: SIL International. Available at http://www.ethnologue.com/ [27 May 2010].

Gottlieb, N., 2001. Language planning and policy in Japan. In: N. Gottlieb and P. Chen, eds Language planning and language policy. East Asian perspectives. London: Curzon, 21-48.

Gottlieb,N. and Chen, P., 2001. Language planning and language policy. East Asian perspectives. London: Curzon.

Graddol, D., 2006. English next. London: British Council.

Grenoble, L.A. and Whaley, L. J., eds 1998. Endangered languages: language loss and community response. Cambridge: Cambridge University Press.

Grin, F., 2003. Language policy evaluation and the European Charter for Regional and Minority Languages. London: Palgrave Macmillan.

Hau, C.S. and Tinio, V. L., 2003. Language policy and ethnic relations in the Philippine. In: M. E. Brown and S. Ganguly, eds Fighting words: language policy and ethnic relations in Asia. Cambridge, MA and London: MIT Press, 319-349.

Held, D., McGrew, A., Goldblatt, D. and Perraton, J., 1999. Global transformations: politics, economics and culture. Stanford, CA: Stanford University Press.

Hinton,L. and Hale, K., eds 2001. The green book of language revitalization in practice. San Diego, CA: Academic Press.

Hopkins, A. G., 2002. Globalization in world history. London: Pimlico.

Hutchins, E., 1995. Cognition in the wild. Cambridge, MA: MIT Press.

International Society of Ethnobiology n.d. Declaration of Belém. Available at: http://www.ethnobiology.net/_common/docs/DeclarationofBelem.pdf [28 May 2010].

Kachru, B. B., 1983. The Indianization of English: the English language in India. Delhi, New York and Oxford: Oxford University Press.

Kachru, B. B., ed. 1986. The alchemy of English: the spread, functions, and models of non-native Englishes. Oxford Pergamon Institute of English.

Kachru, B. B., 2005. Asian Englishes: beyond the canon. Hong Kong: Hong Kong University Press.

Kramsch, C., 2004. Language, thought, and culture In: A. Davies and C. Elder, eds The handbook of applied linguistics. Oxford: Blackwell, 235-262.

Krauss, M., 1992. The world's languages in crisis. Language, 68 (1), 6-10.

Lo Bianco, J., 2005. Globalisation and national communities of communication. Language problems and language planning, 29 (2), 109-133.

Lo Bianco, J., 2007a. Language, place, and learning: PASCAL Observatory, Hot Topic number 17 August 2007, http://www.obs-pascal. com/system/files/Joe+Lo+ Bianco+-++Language+Place+ and+Learning+-+August+ 2007.pdf [28 May 2010].

Lo Bianco, J., 2007b. The emergence of Chinese. Language Policy, 6 (1).

Maffi, L., ed. 2001. On biocultural diversity: linking language, knowledge and the environment. Washington, DC: Smithsonian Institution Press.

Mühlhäusler, P., 1996. Linguistic ecology: language change and linguistic imperialism in the Pacific region. London: Routledge.

Nettle, D. and Romaine, S., 2000. Vanishing voices: the extinction of the world's languages. Oxford: Oxford University Press.

Oviedo, G., Maffi, L. and Larsen, P., 2000. Indigenous and traditional peoples of the world and ecoregion conservation. Gland: WWF and Terralingua.

Rieber, R. W., ed. 1989. The individual, communication, and society: essays in memory of Gregory Bateson. Cambridge: Cambridge University Press.

Robins, R. H. and Uhlenbeck, E., eds 1991. Endangered languages. Oxford: Berg.

Rogoff, B., 2003. The cultural nature of human development. New York: Oxford University Press.

Rohsenow, J. S., 2004. Fifty years of script and written language reform in the PRC: the genesis of the language law of 2001. In: M. Zhou and H. Sun, eds Language policy in the People's Republic of China, theory and practice since 1949. Dordecht: Kluwer, 21-45.

Ruiz, R., 1984. Orientations in language planning. National Association for Bilingual Education Journal, 8 (2), 15-34.

Scanlon, C. and Singh, M., 2006. "Theorizing the decline of linguistic diversity", International Journal of the Sociology of Language, 182, 1-24.

Schmidt, A., 1993. The loss of Australia's aboriginal language heritage. Canberra: Aboriginal Studies Press.

Sharifian, F., 2003. On cultural conceptualizations. Journal of Cognition and Culture, (3) 3, 187-207.

Skutnabb-Kangas, T., 1998. Human rights and language wrongs - a future for diversity?. Language 
Sciences, 20 (1), 5-27.

Skutnab-Kangas, T., Maffi, L. and Harmon, D., 2003. Sharing a world of difference: the earth's linguistic, cultural and biological diversity. UNESCO, WWF and Terralingua. Paris: UNESCO.

Song, J. J., 2001. North and South Korea: language policies of divergence and convergence. In: N. Gottlieb and P. Chen, eds Language planning and language policy. East Asian perspectives. London: Curzon, 129-158.

Suarez-Orozco, M.M. and Baolian Qin-Hilliard, D., 2004. Globalization, culture and education in the new millennium. Berkeley, CA: University of California Press.

Tyler, T. R., 2001. Procedural strategies for gaining deference. In: J. M. Darley, D. M. Messick and T. R. Tyler, eds Social influences on ethical behaviour in organizations. Mahwah, NJ: Erlbaum, 69-86.

Valsiner, J., 2007. Culture in minds and societies: foundations of cultural psychology. Thousand Oaks, CA: Sage.

Valsiner, J. and van der Veer, R., 2000. The social mind: construction of the idea. Cambridge and New York: Cambridge University Press.

Walsh, M., 2005. Will indigenous languages survive?. Annual Review of Anthropology, 34 (1), 293315.

Wierzbicka, A., 2006. English: meaning and culture. Oxford: Oxford University Press.

Wurm, S. A., ed. 2001. Atlas of the world's languages in danger of disappearing. 2nd edn. Paris: UNESCO. 


\section{University Library}

\section{- M M I N E R VA A gateway to Melbourne's research publications}

Minerva Access is the Institutional Repository of The University of Melbourne

Author/s:

Lo Bianco, J

Title:

The importance of language policies and multilingualism for cultural diversity

Date:

2010-03-01

Citation:

Lo Bianco, J. (2010). The importance of language policies and multilingualism for cultural diversity. International Social Science Journal, 61 (199), pp.37-67. https://doi.org/10.1111/ j.1468-2451.2010.01747.x.

Persistent Link:

http://hdl.handle.net/11343/113565 